\title{
DEALING WITH A PATIENT WITH A PROFOUND CONGENITAL
} DEFECT

\author{
M. S. Mabaso, L. R. Uys
}

\section{Case Study 15}

Miss $\mathrm{O}$ is a 23 year old unmarried sister of an 8 year old boy diagnosed as having microcephaly. The family lives in a shanty house ('Umjondolo') at Kwa Makhutha but uses a relative's house for the official address because the family is not entitled to health care locally if they are not registered as residents. Miss O's parents died when her brother was only 6 months old and she was 15 .

"We were 8 in the family, 4 boys and 4

I am the eldest and this boy was my mother's last child. I was not aware that the baby had a problem when he was still very small. As I grew older I noticed that his head was small but I thought he just had a small head which was relatively normal. I had to assume the responsibility of taking care of my younger brothers and sisters as the older sister.

When I was 17 years of age we still did not have any means of support. Relatives and neighbours gave us food when we were hungry and I started selling 'Juba' and beers. After 2 years the child was still unable to crawl, walk or hear. I then realised that the child's growth and development was slow. With the advice of friends and neighbours, I took my brother to King Edward VIII hospital where he stayed for 2 months. We could not visit him often because we did not have money but the nurses gave him injections and did some tests. After he was discharged I took him to Prince Mshiyeni hospital when he was r. Vell and he would be treated for minor ailments there. I was then told that the baby is microcephalic and that he would be retarded mentally. He was then referred to a social worker and they recommended admission at Ekuhlengweni sanatorium. At Ekuhlengweni I was told that admission of this child would depend on two factors. Firstly a single care grant must be organised before admission could be considered and secondly, a vacancy had to be available at the institution.

Ekuhlengweni is always full and they would not take a new case unless somebody was discharged or died and patients are seldom discharged.

It would be better if I could take him there in the morning and collect him in the afternoons although it would be difficult to pay for the transport. I think he would benefit if he could learn skills and to be able to look after himself when he is much older."

Researcher: "What kind of skill are you referring to?"

Respondent: "I do not know. Anything that he can do according to his potential. The health care providers would know better. I have a problem with filling in the forms for a single care grant. I am told that the reason why we do not succeed in having them processed effectively is because the forms must be submitted for approval within 7 days of the first signature. They must be signed by the doctor making a diagnosis, the district surgeon and the magistrate. Another condition is that two authorities are not allowed to sign on the same day. A third condition is that the forms must reach Pietermaritzburg before 7 days is over for approval. Sometimes I do not have money to go day after day to be attended to by all these authorities to be able to submit the forms within the required time. When you go to these authorities for a signature the queues are usually very long and sometimes you are not even attended to on the same day. I may even have borrowed the money for bus or taxi fare. I have already applied 5 times and each time I have been told to go and start all over again. I have heard others say they have applied 8 times and turned down 8 times. Some give up applying for this single care grant. I am supposed to go and check whether my last application has been approved on Monday. I know that I will be told again that the forms arrived late at Pietermaritzburg and I must start again applying by filling in fresh forms and going to get signatures. I am not literate, I am being sent up and down from doctor to doctor and being made to repeat the whole exercise. I do not understand this 7 day delay. Is it possible that something can be done about it? Why do we have to fill in these forms all over again if there is a 7 day delay?"

\section{Reaction of Sister}

"I was very upset when I noticed that my brother was abnormal. Of course I would not have taken him to hospital if I was not adversely affected. I have two other children of my own, I must divide my attention between my children and my mother's abnormal child. I am neither married nor employed and it is quite a tough life for a family without any visible means of support".

\section{Effects on the Family}

"I cannot go to work because of my two children and particularly because of my abnormal brother. I have to look after my mother's family as well because both my parents are dead. The presence of this child has already hampered us financially especially because his single care grant is not yet paid out. The financial burden will be eased once my brothers and sisters are working. Presently I am selling kaffir beer and 'ijuba' to get food. We live in a shack and my mother's friend has been kind enough to allow me to use her home address so that I can apply for a single care grant, otherwise I would not qualify for it".

\section{Socio Cultural Factors}

"I do belong to the Salvation Army church and I believe that God has given us this child, I do not suspect anybody or any witchcraft".

Responses from Health Care Providers "The nurses and doctors are good to us when we go to the hospital and we are attended to in turn. I have not had any nasty experience I can relate with regards to responses from health care providers except for the way in which there is a delay in the forms filled in for a single care grant. There is also a delay in that my brother should be learning some skills and at the moment he is growing up without learning how to take care of himself".

\section{Available Health Care Facilities}

"I know about hospitals such as King Edward VIII, clinics such as Kwa Makhutha and special hospitals such as Ekuhiengweni. I think that these facilities are effective. We found the doctors, the nurses and social workers who attended to us very helpful".

The Ethics of Abortion and Euthanasia "I would not agree to an abortion if this was my baby. I would not agree to euthanasia and I would be willing to take care of the baby".

\section{Other Observations}

At the third visit an interview with a neighbour revealed that they had moved house. There was a fight in the area and their shanty house was burnt down so that they had to flee for their lives. The family could not be traced.

\section{Questions for your consideration}

1. Evaluate the effectiveness of the interventions of the following registered nurses:

1.1 at prince Mshiyeni Hospital.

1.2 at Ekuhlengweni Sanatorium.

If you do not think these were adequate, what could they have done?

2. Since it would seem that the procedure for obtaining single care grant is not possible for poor Black people, what do you think the response of registered nurses should be:

2.1 when they have contact with a patient needing one.

2.2 as an organized profession.

3. What do you think a good service for this group of patients and their families should consist of and how can that be achieved? 